\title{
Computational Prediction of Speciation Diagrams and Nucleation Mechanisms: Molecular Vanadium, Niobium and Tantalum Oxide Nanoclusters in Solution
}

\author{
Enric Petrus $¥$, Mireia Segado-Centellast, Carles Bo*†‡ \\ †Institute of Chemical Research of Catalonia (ICIQ), The Barcelona Institute of Science and Technology (BIST), Av. Països \\ Catalans, 16, 43007 Tarragona, Spain \\ ‡Departament de Química Física i Inorgánica, Universitat Rovira i Virgili, Marcel•lí Domingo s/n, 43007 Tarragona, Spain E- \\ mail: cbo@iciq.cat
}

\begin{abstract}
Understanding the aqueous speciation of molecular metal-oxo clusters plays a key role in different fields such as catalysis, electrochemistry, nuclear waste recycling, and biochemistry. To accurately describe the speciation, it is essential to elucidate the underlying self-assembly processes. Herein, we apply a computational method to predict the speciation and formation mechanisms of polyoxovanadates, -niobates and -tantalates. While polyoxovanadates have been widely studied, polyoxoniobates and -tantalates lack the same level of understanding. In the first place, we proposed a pentavanadate cluster $\left(\left[\mathrm{V}_{5} \mathrm{O}_{14}\right]^{3-}\right)$ as a key intermediate for the formation of the decavanadate. Our computed phase speciation diagram is in particularly good agreement with the experiments. Secondly, we report the formation constants of the heptaniobate, $\left[\mathrm{Nb}_{7} \mathrm{O}_{22}\right]^{9-}$, decaniobate, $\left[\mathrm{Nb}_{10} \mathrm{O}_{28}\right]^{6-}$, and tetracosaniobate $\left[\mathrm{H}_{9} \mathrm{Nb}_{24} \mathrm{O}_{72}\right]^{9-}$. Additionally, we have computed the speciation and phase diagram of niobium, which so far was restricted to Lindqvist derivates. Finally, we have predicted the formation constant of the decatantalate $\left(\left[\mathrm{Ta}_{10} \mathrm{O}_{26}\right]^{6-}\right)$ in water, even though it had only been synthetized in toluene. Furthermore, the corresponding speciation and phase diagrams for polyoxotantalates have been also calculated. Overall, we show that our method can be successfully applied to different families of molecular metal oxides without any need for readjustments; therefore, it can be regarded as a trustworthy tool for exploring polyoxometalates' chemistry.
\end{abstract}

\section{INTRODUCTION}

Metal oxides and molecular-oxo clusters are key materials for the development of both current and future technologies. ${ }^{1-4}$ These materials are usually prepared by crystallization of a solution containing molecular metal-oxo clusters. ${ }^{5}$ However, how these compounds are formed in aqueous media, and how high nuclearities are obtained remain unclear. ${ }^{6}$ This is because the self-assembly of metal-oxo clusters in water is affected by several variables: temperature, $\mathrm{pH}$, ionic force, concentration and counterions. ${ }^{7}$ One prominent type of molecular metal oxides are polyoxometalates (POMs). These polynuclear clusters consist of group $\mathrm{V}$ and $\mathrm{VI}$ metals at high oxidation states and with multiple oxo-ligands. Group VI POMs have been studied extensively with an assemble via bottomup route. ${ }^{8,9}$ Larger structures are formed by just acidifying the molybdenum and tungsten monomeric precursors. In contrast, Group $\checkmark$ POMs show a different assembly process. On the one hand, a bottom-up approach is also followed to obtain polyoxovanadates. For instance, increasing the $\mathrm{pH}$ of a solution of the vanadium precursor yields larger structures, such as the decavanadate $\left(\left[\mathrm{V}_{10} \mathrm{O}_{28}\right]^{6-}\right.$ $;\left\{\mathrm{V}_{10}\right\}$, Figure 1). On the other hand, polyoxoniobates and -tantalates have a top bottom route because of the lack of a stable monomeric precursor. This is due to the larger size and lower charge-densities of $\mathrm{Nb}^{5+}$ and $\mathrm{Ta}^{5+}$, compared to $\mathrm{V}^{5+}, \mathrm{Mo}^{6+}$ and $\mathrm{W}^{6+} .{ }^{10}$ Thus, niobium and tantalum oxides only form the Lindqvist ion $\left(\left[\mathrm{M}_{6} \mathrm{O}_{19}\right]^{8} ;\left\{\mathrm{M}_{6}\right\} \mathrm{M}=\mathrm{Nb} / \mathrm{Ta}\right.$, Figure 1a) in highly alkaline solution. ${ }^{11}$

Vanadium aqueous speciation was first described thirty years ago thanks to the direct accessibility to ${ }^{51} \mathrm{~V}$ NMR and potentiometric titration studies. ${ }^{12,13}$ It is well-established that oligomers with one to five vanadium atoms are formed in solutions of $\mathrm{pH}>6$. At lower pHs only the decavanadate, $\left\{\mathrm{V}_{10}\right\}$, and $\left[\mathrm{VO}_{2}\right]^{+}$has been reported. Polyoxovanadates are the lightest class of molecular oxides available. They display high gravimetric energy densities, which is a key factor for electron mobility applications. ${ }^{14}$ Additionally, vanadium has multiple oxidization states $\left(\mathrm{V}^{5+} / \mathrm{V}^{4+}\right.$ and $\left.\mathrm{V}^{4+} / \mathrm{V}^{3+}\right)$, which enables rich redox chemistry. These features combined make vanadium oxo-clusters very promising compounds for batteries. ${ }^{15,16}$ Decavanadate has been the main prototype for electrochemical studies. To cope with thermal degradation of the metal-oxo cluster, Streb and coworkers prepared a supramolecular crystal that stabilized the decavanadate in a lattice. ${ }^{17}$ Moreover, polyoxovanadates are sensitive to the visible-light region, which makes them suitable for photoredox catalysis. ${ }^{18}$ For example, a molecular manganese vanadium oxide cluster exhibits water oxidation in the natural photosystem-II. ${ }^{19}$ Vanadium oxo-clusters also play important roles in biological processes. ${ }^{20,21}$ There are three remarkable isopolyoxovanadates that have demonstrated antibacterial properties: vanadium oxide, $\left[\mathrm{VO}_{4}\right]^{3-}$, tetravanadate $\left(\left[\mathrm{V}_{4} \mathrm{O}_{12}\right]^{4-} ;\left\{\mathrm{V}_{4}\right\}\right.$, 
Figure $1 \mathrm{~d}$ ) and decavanadate $\left\{\mathrm{V}_{10}\right\} .{ }^{22}$ Nonetheless, the decavanadate is the most prominent cluster due to its high biological activity and antitumor properties. ${ }^{23,24}$

Despite vanadium, niobium and tantalum belonging to the same group in the periodic table, polyoxoniobates and tantalates have a different behavior in aqueous solution, compared to polyoxovanadates. In fact, niobium and tantalum oxo-clusters only form in neutral and alkaline conditions. In addition, niobium and tantalum molecular oxides display anomalous solubility trends in the presence of alkaline ions. For instance, cesium niobate and tantalate salts are more soluble than their lithium analogs. ${ }^{7}$ Niobium oxo-cluster chemistry has experienced great success in the past decade and new compounds beyond $\left\{\mathrm{Nb}_{6}\right\}$ and $\left\{\mathrm{Nb}_{10}\right\}^{25}$ have been characterized. In fact, just the list of isopolyoxoniobates has increased considerably: $\left(\left[\mathrm{Nb}_{7} \mathrm{O}_{22}\right]^{9-} ;\left\{\mathrm{Nb}_{7}\right\}, \mathrm{Figure}_{1 \mathrm{~b}}\right)^{26},\left(\left[\mathrm{Nb}_{24} \mathrm{O}_{72} \mathrm{H}_{9}\right]^{9-}\right.$; $\left\{\mathrm{Nb}_{24}\right\}$, Figure $\left.1 \mathrm{~h}\right),{ }^{27}\left(\left[\mathrm{HNb}_{27} \mathrm{O}_{76}\right]^{16-} ;\left\{\mathrm{Nb}_{27}\right\}\right),{ }^{28}\left[\mathrm{Nb}_{32} \mathrm{O}_{96}\right]^{32-},{ }^{29}\left[\mathrm{Nb}_{52} \mathrm{O}_{150}\right]^{40-}, 30$ and $\left[\mathrm{Nb}_{54} \mathrm{O}_{151}\right]^{32-31}$ These discoveries have important implications in expanding the main applications of niobium oxo-clusters in radioactive waste management ${ }^{32}$ and catalysis. ${ }^{33,34}$ On the other hand, polyoxotantalate chemistry remains underexplored, partly due to slow reaction kinetics and poor solubility in water. ${ }^{35}$ This lack of development is exemplified by the low number of reported tantalate species. ${ }^{36} \mathrm{Only}_{\text {the }}$ Lindqvist $\left(\left[\mathrm{Ta}_{6} \mathrm{O}_{19}\right]^{8-}\right.$; $\left\{\mathrm{Ta}_{6}\right\}$ Figure 1a) is observed for isopolyoxotantalates compounds in aqueous solution. ${ }^{37,38}$ Furthermore, the decatantalate $\left(\left[\mathrm{Ta}_{10} \mathrm{O}_{28}\right]^{6-} ;\left\{\mathrm{Ta}_{10}\right\}\right.$ Figure 1f) has only been isolated in non-aqueous media. ${ }^{39}$ Despite that, controlling polyoxotantalate speciation is a promising asset for synthetizing solid materials. Indeed, tantalum oxides have excellent applications in photocatalysis ${ }^{40}$ and technological materials such as transistors. ${ }^{41}$

(a)

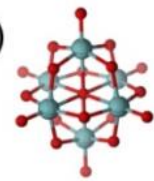

(d)

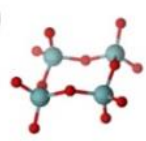

(b)

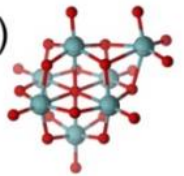

(e)

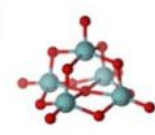

(c)

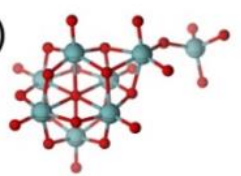

(f)

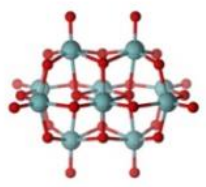

(g)

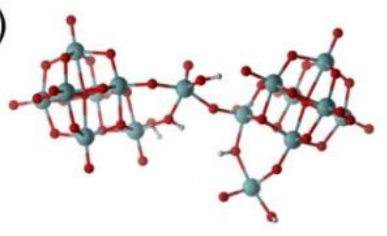

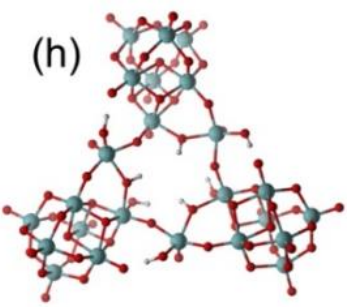

Figure 1. Representative structures for vanadium, niobium, and tantalum oxo-clusters. Ball sticks representation of (a) Lindqvist $\left[\mathrm{M}_{6} \mathrm{O}_{19}\right]^{8-}$ $\left(\left\{\mathrm{M}_{6}\right\}\right),(\mathrm{b})\left[\mathrm{M}_{7} \mathrm{O}_{22}\right]^{9-}\left\{\mathrm{M}_{7}\right\},(\mathrm{c})\left[\mathrm{M}_{8} \mathrm{O}_{25}\right]^{10-}\left\{\mathrm{M}_{8}\right\}$, (d) $\left[\mathrm{M}_{4} \mathrm{O}_{12}\right]^{4-}\left\{\mathrm{m}-\mathrm{M}_{4}\right\},(\mathrm{e})\left[\mathrm{M}_{5} \mathrm{O}_{14}\right]^{4-}\left\{\mathrm{M}_{5}\right\}$ (f) decametalate $\left[\mathrm{M}_{10} \mathrm{O}_{28}\right]^{6-}\left\{\mathrm{M}_{10}\right\},(\mathrm{g})\left[\mathrm{HM} \mathrm{M}_{16} \mathrm{O}_{49}\right]\left\{\mathrm{M}_{16}\right\}$, (h) $\left[\mathrm{H}_{9} \mathrm{M}_{24} \mathrm{O}_{72}\right]_{9-}\left\{\mathrm{M}_{24}\right\}$.

Solving the speciation of metal oxides in solution is intimately related to describing the chemical reaction network (CRN) that connects all possible stable species and the corresponding reaction intermediates. Polyoxometalates' reaction networks mainly consist of two types of reactions: acid-base equilibria and aggregations. Thus, if we find which reactions happen in solution, we will be able to predict the relative abundance of each metal-oxo species. In the past decades, quantum mechanical calculations have succeeded in predicting the chemical properties and the reactivity of POMs. ${ }^{42}$ The study of complex reaction mechanisms relying solely on human intuition is time-consuming and prone to error. Consequently, new alternative approaches try to automate the discovery of reaction mechanisms. ${ }^{43}$ Recently, there has been an increase of automated methods that are being applied to different fields such as prebiotics, ${ }^{44}$ combustion, ${ }^{45}$ solid-state synthesis ${ }^{46}$ and decomposition reactions. ${ }^{47}$ Following this trend, we have recently reported the development of a new method, called POMSimulator, that automatically generates the CRN for a set of metal-oxo clusters from raw quantum chemical results and predicts both speciation diagrams and the corresponding reaction mechanism. ${ }^{48}$ Hitherto, we have applied this method to polyoxomolybdates and -tungstanates with excellent results. ${ }^{49}$

In this work, we exploit the capabilities of POMSimulator to predict the aqueous speciation and nucleation mechanisms of Group $\mathrm{V}$ polyoxometalates. We have considered 122 metal-oxo clusters in total, including classical structures such as Lindqvist $\left\{\mathrm{M}_{6}\right\}$ and decametalate $\left\{\mathrm{M}_{10}\right\}$. In addition, we have also explored other non-reported species: pentametalate $\left(\left[\mathrm{M}_{5} \mathrm{O}_{14}\right]^{3-;}\left\{\mathrm{M}_{5}\right\}\right)$, octametalate $\left(\left[\mathrm{M}_{8} \mathrm{O}_{25}\right]^{10-} ;\left\{\mathrm{M}_{8}\right\}\right.$ Figure $\left.1 \mathrm{c}\right)$ and hexadecametalate $\left(\left[\mathrm{M}_{16} \mathrm{O}_{49}\right]^{18-} ;\left\{\mathrm{M}_{16}\right\}\right.$ Figure $\left.1 \mathrm{~g}\right)$. Scheme 1 sketches the main steps of our method. Firstly, it obtains free energies at a Density Functional Theory (DFT) level and captures bonding information from the electron density for each species. Then, it generates the chemical reaction network for each POM family. Next, it sets up and solves many 
multi-species chemical equilibria (MSCE). Finally, we decide the best speciation model, and infer its reaction mechanism. A detailed description of the methods and computational details is included in the Supporting Information.

\section{RESULTS AND DISCUSSION}

\section{Aqueous Speciation}

We have defined three molecular sets for polyoxovanadates, -niobates and-tantalates. Our vanadium molecular set is formed by 16 different topologies. If we consider all the protonation states, the final number of species is 42 metal-oxo clusters. It has the classical decavanadate, $\left\{V_{10}\right\}$ as well as the Lindqvist $\left\{V_{6}\right\}$. Furthermore, we have included cyclic structures (also known as metavanadates): $\left[\mathrm{V}_{3} \mathrm{O}_{9}\right]^{3-},\left[\mathrm{V}_{4} \mathrm{O}_{12}\right]^{4-},\left[\mathrm{V}_{5} \mathrm{O}_{15}\right]^{5-},\left[\mathrm{V}_{6} \mathrm{O}_{18}\right]^{6-},\left[\mathrm{V}_{7} \mathrm{O}_{21}\right]^{7-},\left[\mathrm{V}_{8} \mathrm{O}_{24}\right]^{8-}$ and $\left[\mathrm{V}_{9} \mathrm{O}_{27}\right]^{9-}$. These cyclic structures will be denoted as $\{m-$ $\left.V_{n}\right\} ; m$ refers to "metavanadate" and $n$ to the number of metal atoms. Secondly, niobium and tantalum molecular sets share the same 42 structures, just differing in the metal centers, plus monomeric hydroxides, $\left[\mathrm{M}(\mathrm{OH})_{\mathrm{x}}\right]^{(5 \cdot x)}$, condensed forms of the Lindqvist structures, $\left\{M_{7}\right\},\left\{M_{8}\right\},\left[M_{9} O_{27}\right]^{9-}\left\{M_{9}\right\}$, and medium-large clusters such as $\left\{M_{16}\right\}$ and $\left\{M_{24}\right\}$. Although some structures are unique for each system, there are common structures in the three sets of polyoxometalates. For example, vanadium, niobium and tantalum share the same decametalates, and Lindqvist structures. In this manner, we ensure that we are not biasing the simulation towards a specific product. In addition, we have included cyclic compounds in the niobium and tantalum sets, despite there is no experimental evidence that they exist in solution. Thereby, we can test whether our method detects the inherently different chemistry of each metal automatically. Additionally, we have included non-reported species, such as the $\left[\mathrm{M}_{5} \mathrm{O}_{14}\right]^{4-}\left(\left\{\mathrm{M}_{5}\right\}\right.$, Figure $\left.1 \mathrm{e}\right)$ and $\left\{\mathrm{M}_{16}\right\}$ to investigate the existence of possible transient intermediates. A detailed overview of the complete molecular set with the DFT optimized tridimensional structures can be found in Figure S1. A dataset collection ${ }^{50}$ of the main results is available in the ioChem-BD repository. ${ }^{51}$

In the first place, we computed the CRN for vanadium, niobium, and tantalum oxides, which are formed by 75,65 and 65 chemical reactions, respectively. We started by converting the molecules to molecular graphs. Then, we mapped the isomorphic property to decide which molecules could be potentially related by a chemical reaction. We have defined five types of reactions: acid/base equilibria, hydrolysis, condensation, addition and dimerization. The complete lists of reactions, with their corresponding free energies, are collected in Table S1, S2 and S3. Next, we moved to the resolution of the multi-species chemical equilibria (MSCE). We set up $1.1 \cdot 10^{6}, 4.7 \cdot 10^{5}$ and $5.2 \cdot 10^{5}$ speciation models for vanadium, niobium, and tantalum, respectively. We solved every speciation model at different $\mathrm{pH}$ values, thus obtaining new sets of formation constants at each $\mathrm{pH}$. Although formation constants are formally independent of the $\mathrm{pH}$, there are small numeric fluctuations. Therefore, to decrease the margin of error, we increased the sample size by solving the speciation models multiple times. More precisely, we solved $7.5 \cdot 10^{7}, 6.9 \cdot 10^{7}$ and $8.6 \cdot 10^{7}$ systems of non-linear equations (NLE) and then we estimated the equilibrium constants of all the metal-oxo compounds (see Figures S6, S7 and S8).

The resulting theoretical formation constants already provide meaningful information in terms of chemical properties. Polyoxoniobates have larger formation constants than tantalates. Therefore, we deduced that niobium oxide clusters are more stable than tantalum oxides clusters. This evidence is in good agreement with the enthalpy data reported experimentally. ${ }^{52}$ However, DFT formation constants cannot be directly used to predict the aqueous speciation. This is so because theoretical constants are overestimated with respect to the experimental values. ${ }^{49,53}$ For molybdenum and tungsten oxides, we have recently found a strong linear dependence between DFT and empirical formation constants, thus granting the application of a systematic linear scaling. ${ }^{54}$ Therefore, the first milestone for predicting Group $V$ aqueous speciation depended on the accuracy of the linear scaling.

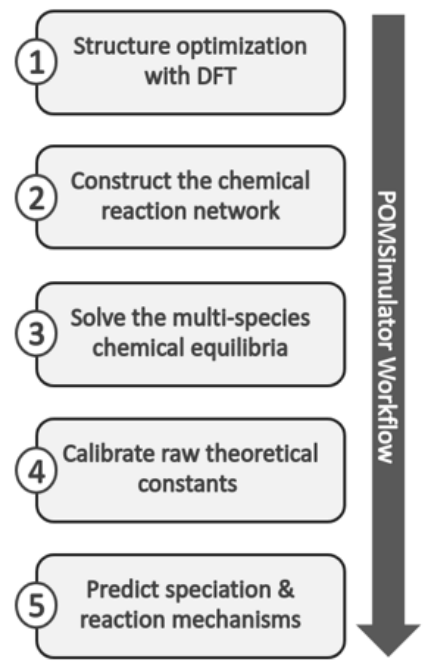


Scheme 1. POMSimulator's main workflow: 1) perform structure optimizations of metal-oxo clusters 2) find all the chemical reactions, including acid-base equilibria and polymerizations 3) solve the speciation models 4) calibrate the DFT equilibrium constants with a linear rescale 5) employ the rescaled constants to predict the speciation and the reaction mechanisms.

We chose as references eleven polyoxovanadates formation constants reported by Elvingson et al., ${ }^{55}$ three polyoxoniobates constants reported by Etxebarria et al., ${ }^{56}$ and three polyoxotantalates constants reported by Deblonde and coworkers. ${ }^{11}$ Analysis of the linear regressions in Figure 2 shows that the linear scaling works for Group $\mathrm{V}$ polyoxometalates. Figure $2 \mathrm{~A}$ shows the best linear regression for the vanadate oxides $\left(R^{2}=0.9995\right.$; $\left.R M S E=0.44\right)$. It is remarkable that the calibration is so accurate even though there are eleven points in the sample. Additionally, different topologies were included: monomeric compounds, $\left[\mathrm{VO}_{4}\right]^{3-},\left[\mathrm{HVO}_{4}\right]^{2-}$, $\left[\mathrm{VO}_{2} \cdot 3 \mathrm{H}_{2} \mathrm{O}\right]^{+}$, cyclic structures $\left\{\mathrm{m}-\mathrm{V}_{4}\right\}\left\{\mathrm{m}-\mathrm{V}_{5}\right\}$, and decavanadates, $\left\{\mathrm{H}_{2} \mathrm{~V}_{10}\right\},\left\{\mathrm{HV} \mathrm{V}_{10}\right\},\left\{\mathrm{V}_{10}\right\}$. On the other hand, the calibrations for the polyoxoniobates and -tantalates are slightly different than for -vanadates because fewer experimental data are available for niobium. In fact, we could only find formation constants for the three Lindqvist structures: $\left\{H_{3} M_{6}\right\},\left\{H_{2} M_{6}\right\}$, and $\left\{H M M_{6}\right\}(w h e r e ~ M=N b$ and $\mathrm{Ta}$ ). Due to the small size of the sample, we could not rely exclusively on the RMSE and $\mathrm{R}^{2}$ to decide the best linear scaling. Therefore, we performed a deeper analysis of the regressions to estimate the best rescale (details in the supporting information).
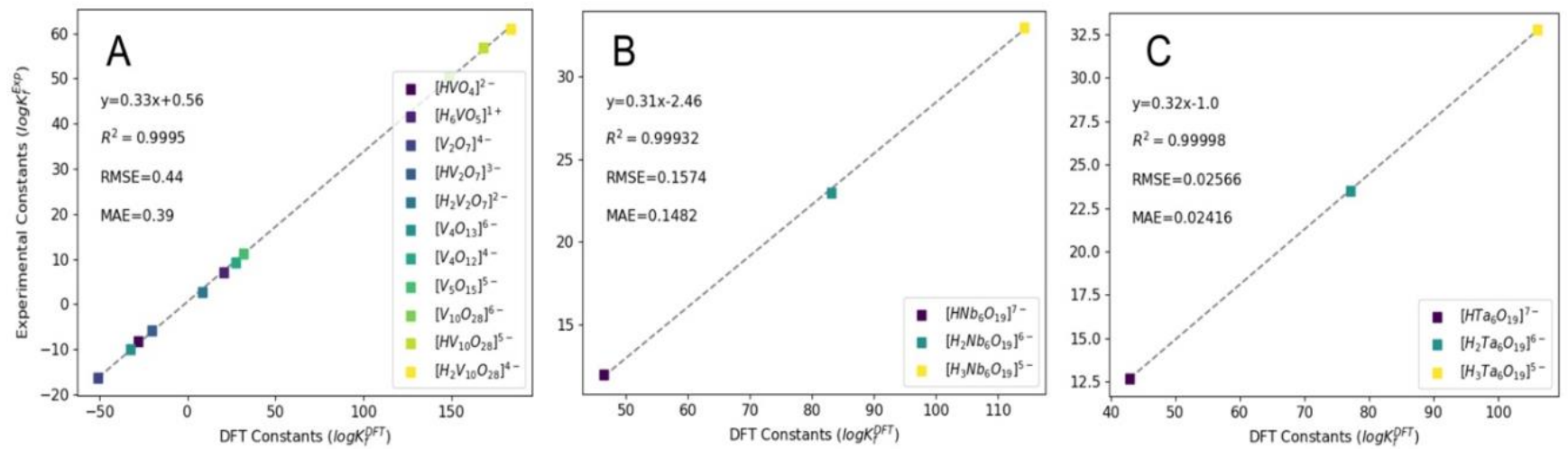

Figure 2. Linear regressions between log $\mathrm{Kf}^{\mathrm{Exp}}$ and log $\mathrm{Kf}{ }^{\mathrm{DFT}}$. Lowest root mean squared error (RMSE) and mean average (MAE) values at $298.15 \mathrm{~K}$ and $1 \mathrm{~atm}$ for polyoxovanadates (A) and -niobates (B) and -tantalates (C), at 0.25, 0.1 and $1.0 \mathrm{M} \mathrm{NaCl}$ ionic strengths, respectively.

Figure $2 \mathrm{~B}$ collects the calibration equation that leads to the best agreement with polyoxoniobate speciation. It has low root mean squared $(R M S E=0.025)$ and mean average $(M A E=0.024)$ errors, as well as a high determinant coefficient $\left(R^{2}=0.99998\right)$. Then, Figure 2C, shows the calibration equation that provides a best match with the experimental tantalate data. It has a low root mean squared $(R M S E=0.15)$ and mean average $(M A E=0.14)$ errors and a remarkably high determinant coefficient $\left(R^{2}=0.9993\right)$. Once we have chosen the best linear scaling, we could introduce the rescaled constants to the speciation models.

Figure 3 shows the potential of POMSimulator for supplying a complete picture of the POMs speciation. To do so, we have considered not only the free reaction energy at a given temperature, but also the $\mathrm{pH}$, ionic force and concentration effects. The top part of Figure 3 depicts phase speciation diagrams, which pinpoint the most abundant oxo-clusters depending on both the $\mathrm{pH}$ and the total metal concentration. These plots are extremely helpful for guiding experiments since they specify the conditions to synthetize a given compound. Even if phase speciation diagrams supply great insights into polyoxometalates' aqueous behavior, the examples reported in the literature are scarce. Therefore, filling this gap is paramount to unveil the speciation of polyoxometalates. On the other hand, the bottom part of Figure 3 shows simple speciation diagrams, which collect information of all relevant species at a fixed metal concentration but variable $\mathrm{pH}$. They are useful for detecting minor species and transient intermediates involved in the formation of larger polyoxometalates. In fact, speciation diagrams are still one of the most employed tools for studying these systems. Overall, both types of plots have an excellent synergy, since they reveal the intricate effect of pH and concentration on the oxo-clusters formation. Secondly, we focused on the speciation of polyoxoniobates. Initially, the aqueous behavior of polyoxoniobates was very much restricted to Lindqvist structures: $\left\{\mathrm{H}_{\mathrm{x}} \mathrm{Nb}_{6}\right\}$. This was mainly due to the poor solubility of niobate salts in water, especially at low pH. Despite the poor solubility and the unusual alkaline speciation, experimental techniques have succeeded in detecting new polyoxoniobates in solution over the past ten years. ${ }^{23}$ The chemistry of niobium is vastly different from its neighbors in the periodic table. As we mentioned before, the charge size ratio has a strong influence on the speciation of polyoxometalates. This fact involves a dramatic change in the aqueous speciation of niobium, compared to classical polyoxometalates, such as molybdates, tungstanates, and vanadates. Figure 3B shows the predicted phase and speciation diagram of the old and new niobium oxo-clusters (at an ionic force of $0.1 \mathrm{M}$ of $\mathrm{NaCl}$ ). To the best of our knowledge, the phase speciation diagram in Figure 3B top is the first that has oxo-clusters that have been discovered over this decade. In other words, the diagrams in Figure 3B include compounds that go beyond the Lindqvist limit. In addition, if we analyze Figure 3B, we see that our method reproduces the alkaline character of polyoxoniobates' chemistry $(\mathrm{pH} 5-14)$ automatically. This is a noteworthy feature, since we 
did not introduce any modification to readjust the program for a completely different $\mathrm{pH}$ behavior. This evidence reinforces our belief that the method used here is a general-purpose tool for predicting the speciation of POMs. The phase speciation diagram in Figure $3 \mathrm{~B}$ reveals that $\left\{\mathrm{Nb}_{10}\right\}$ is the most abundant compound at acid, neutral, and slight alkaline pH. Comparing Figures $3 \mathrm{~A}$ and $3 \mathrm{~B}$, we can also deduce that $\left\{\mathrm{Nb}_{10}\right\}$ is more alkaline than its vanadium analog $\left\{\mathrm{V}_{10}\right\}$, in good agreement with the experiments. ${ }^{57}$ Figure $3 \mathrm{~B}$ top also reveals that, at the similar $\mathrm{pH}$ but higher concentrations, $\left\{\mathrm{Nb}_{24}\right\}$ is formed. The chemical relationship between $\left\{\mathrm{Nb}_{10}\right\}$ and the $\left\{\mathrm{Nb}_{24}\right\}$ was reported in our earlier work in collaboration with May Nyman's research group. ${ }^{58}$ Figure 3B top reproduces well the $\mathrm{pH}$ range (between 8 and 11 ) and the concentration $(2 \mathrm{M})$ at which $\left\{\mathrm{Nb}_{24}\right\}$ was synthesized. Note that the phase diagram only shows the most abundant compounds. Therefore, $\left\{\mathrm{Nb}_{24}\right\}$ can also be detected at more alkaline conditions, even though it is not the most principal compound.
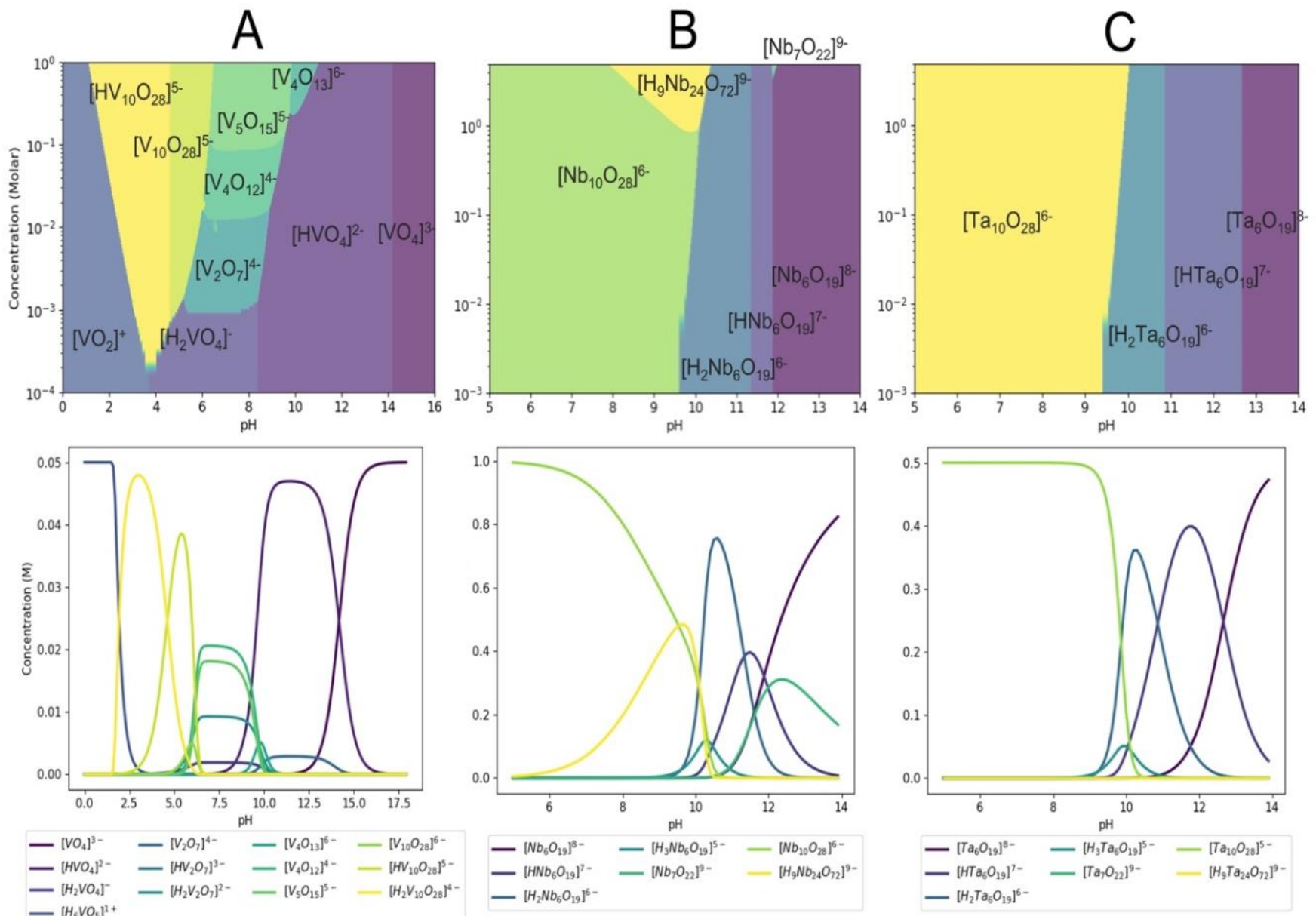

Figure 3. Top: speciation phase diagrams employing scaled $\Delta \mathrm{G}^{\mathrm{DFT}}$ values, at $298.15 \mathrm{~K}$ and $1 \mathrm{~atm}$. $\mathrm{A}$ : polyoxovanadates at I=0.25 $\mathrm{M} \mathrm{NaCl}, \mathrm{B}$ : polyoxoniobates at $\mathrm{I}=0.1 \mathrm{M} \mathrm{NaCl}, \mathrm{C}$ : polyoxotantalates at $\mathrm{I}=1.0 \mathrm{M} \mathrm{NaCl}$ (ionic force value fixed according to the experimental data). The total metal molar concentration is fixed between $10^{0}-10^{4} \mathrm{M}$. Concentration axes are in logarithmic scale. Bottom: speciation diagrams at $0.5 \mathrm{M}$, $1.0 \mathrm{M}$ and $1.0 \mathrm{M}$ metal concentration for vanadium, niobium and tantalum respectively. The speciation diagrams were computed at the same ionic forces than the corresponding phase diagrams.

The formation of $\left\{\mathrm{Nb}_{24}\right\}$ led to the discovery of another relevant niobium cluster: the heptaniobate. ${ }^{26}\left\{\mathrm{Nb}_{7}\right\}$ has a particularly significant role in the formation of larger clusters such as the $\left\{\mathrm{Nb}_{10}\right\}$ and $\left\{\mathrm{Nb}_{24}\right\}$. In fact, our phase diagram also predicts the appearance of the heptaniobate structure, thus supplying the experimental conditions to isolate this compound. However, in Figure $3 \mathrm{~B}$ top $\left\{\mathrm{Nb}_{7}\right\}$ appears at a more alkaline region, far from the $\left\{\mathrm{Nb}_{10}\right\}$ and $\left\{\mathrm{Nb}_{24}\right\}$ areas. At first glance, it is counterintuitive because $\left\{\mathrm{Nb}_{7}\right\}$ is regarded as a key intermediate in the formation of large clusters. However, we attribute this to the thermodynamic stability of $\left\{\mathrm{Nb}_{7}\right\}$ in aqueous solution. For instance, the $\left\{\mathrm{Nb}_{10}\right\}$ and $\left\{\mathrm{Nb}_{24}\right\}$ are the most abundant and stable compounds at neutral pH. Therefore, within this $\mathrm{pH}$ range, $\left\{\mathrm{Nb}_{7}\right\}$ acts as a transient intermediate. That is why it does not appear in a phase diagram since it rapidly reacts to form either the $\left\{\mathrm{Nb}_{10}\right\}$ or $\left\{\mathrm{Nb}_{24}\right\}$. On the other hand, if we are interested in obtaining $\left\{\mathrm{Nb}_{7}\right\}$ as the main product, then we must move to more alkaline conditions. To reinforce this idea, we followed an earlier work by Casey and coworkers ${ }^{59}$ in which they performed an ${ }^{17} \mathrm{O}-\mathrm{NMR}$ starting from a solution of $\left\{\mathrm{Nb}_{10}\right\}$ at $\mathrm{pH}$ ? 12.5 and they detected heptaniobate derivates $\left(\left\{\mathrm{Nb}_{7+\mathrm{x}}\right\}\right)$ throughout the decomposition of $\left\{\mathrm{Nb}_{10}\right\}$. Thus, there is experimental evidence that $\left\{\mathrm{Nb}_{7}\right\}$ is detected at high pH values, in good agreement with our prediction in Figure 3B. According to our phase diagram, $\left\{\mathrm{Nb}_{7}\right\}$ can be only isolated at remarkably high concentrations $(\sim 2 \mathrm{M})$. Nonetheless, Figure $3 \mathrm{~B}$ bottom shows that $\left\{\mathrm{Nb}_{7}\right\}$ is already present at $1 \mathrm{M}$, even though it is not the most 
abundant compound. Given that it is in equilibrium with the very stable Lindqvist structures, it is reasonable to assume that $\left\{\mathrm{Nb}_{7}\right\}$ will hardly become the most dominant cluster. Additionally, we believe it is consistent to find $\left\{\mathrm{Nb}_{7}\right\}$ close to $\left\{\mathrm{Nb}_{6}\right\}$, since their respective structures are extremely similar (see Figures $1 \mathrm{a}$ and $1 \mathrm{~b}$ ). Then, the compounds left in the phase diagram correspond to the well-known Lindqvists. They predominate in most of the alkaline region and are found in different protonation states: $\left\{\mathrm{H}_{2} \mathrm{Nb}_{6}\right\}$, $\left\{\mathrm{HNb}_{6}\right\}$, and $\left\{\mathrm{Nb}_{6}\right\}$. Figure $2 \mathrm{~B}$ already shows that Lindqvist's theoretical formation constants are in excellent agreement with the experimental data. Moreover, note that $\left\{\mathrm{H}_{3} \mathrm{Nb}_{6}\right\}$ does not appear in Figure 3B top, but it does in Figure 3B bottom. Consequently, the triprotonated state of the Lindqvist is regarded as a minority compound, but detectable in solution. The cases of $\left\{\mathrm{Nb}_{7}\right\}$ and $\left\{\mathrm{H}_{3} \mathrm{Nb}_{6}\right\}$ show the importance of providing speciation diagrams along with phase diagrams. In this way, we can obtain a general, and yet detailed picture of the aqueous speciation, without disregarding any oxo-cluster.

Table 1. Computed formation constants for polyoxoniobates and tantalates at an ionic strength of $0.1 \mathrm{M}$ and $1.0 \mathrm{M} \mathrm{NaCl}$.

\begin{tabular}{|l|c|c|}
\hline Compounds $^{\mathbf{a}}$ & $\log \mathbf{K f}(\mathbf{M}=\mathbf{N b})$ & $\log \mathbf{K f} \mathbf{( M = T a )}$ \\
\hline$\left[\mathrm{M}(\mathrm{OH})_{3}\right]^{2+}$ & -12.52 & 1.45 \\
\hline$\left[\mathrm{M}(\mathrm{OH})_{4}\right]^{+}$ & 0.84 & 5.30 \\
\hline $\mathrm{M}(\mathrm{OH})_{5}$ & 4.69 & 6.74 \\
\hline$\left[\mathrm{M}_{6} \mathrm{O}_{19}\right]^{8-}$ & $-2.45^{b}$ & $-0.99^{b}$ \\
\hline$\left[\mathrm{HM}_{6} \mathrm{O}_{19}\right]^{7-}$ & 11.87 & 12.66 \\
\hline$\left[\mathrm{H}_{2} \mathrm{M}_{6} \mathrm{O}_{19}\right]^{6-}$ & 23.21 & 23.52 \\
\hline$\left[\mathrm{H}_{3} \mathrm{M}_{6} \mathrm{O}_{19}\right]^{5-}$ & 32.80 & 32.75 \\
\hline$\left[\mathrm{M}_{7} \mathrm{O}_{22}\right]^{9-}$ & 3.95 & -0.18 \\
\hline$\left[\mathrm{M}_{10} \mathrm{O}_{28}\right]^{6-}$ & 79.40 & 79.09 \\
\hline$\left[\mathrm{M}_{24} \mathrm{O}_{72} \mathrm{H}_{9}\right]^{9-}$ & 185.29 & 174.95 \\
\hline
\end{tabular}

a Constants refer to this formation reaction $\mathrm{p}\left[\mathrm{M}_{6} \mathrm{O}_{19}\right]^{8-}+\mathrm{qH}^{+} \rightleftharpoons\left[\mathrm{H}_{2} \mathrm{M}_{\mathrm{p}} \mathrm{O}_{\mathrm{m}}\right]^{\mathrm{n}-}+(\mathrm{q} / 2+\mathrm{p}-\mathrm{z} / 2) \mathrm{H}_{2} \mathrm{O}$. ${ }^{\mathrm{b}}$ Note that the formation constants of $\left[\mathrm{M}_{6} \mathrm{O}_{19}\right]^{8-}$ are not zero because of the linear scaling $(\mathrm{y}=\mathrm{m} \cdot 0+\mathrm{b})$. Thus, the constants are equal to the intercept values depicted in Figure $2 \mathrm{~B}$ and $2 \mathrm{C}$ respectively.

Finally, we focused on the speciation of polyoxotantalates. The aqueous behavior of tantalum oxo-clusters is the most limited in terms of $\mathrm{pH}$ range and number of species. The main reason lies in the poor solubility of tantalate salts in aqueous solution (even poorer than niobates). In fact, the only species that have been detected experimentally in water are the Lindqvist-derivate compounds, $\left\{\mathrm{H}_{\mathrm{x}} \mathrm{Ta}_{6}\right\}$. At pH lower than 8, the aqueous speciation is hindered due to the formation of the $\mathrm{Ta}_{2} \mathrm{O}_{5} \mathrm{precipitate}$. Despite the difficulties, $\left\{\mathrm{Ta}_{10}\right\}$ was synthesized in non-aqueous media almost ten years ago. ${ }^{36}$ This evidence confirmed that the decametalate structure was also present in tantalum as it is in vanadium and niobium. Further work was done in this direction by Casey and coworkers. They showed that if one or two tantalum atoms were exchanged by titanium, the solubility in water (at neutral pH) increased. ${ }^{38}$ This evidence suggested that the formation of $\left\{\mathrm{Ta}_{10}\right\}$ is deprived because of solubility instead of thermodynamic reasons. This conclusion was further supported by Hatchett who highlighted that insolubility should not imply instability. ${ }^{60}$ Figure $3 \mathrm{C}$ top shows the most abundant clusters in a $\mathrm{pH}$ range between 5 and 14, at acid, neutral and slightly alkaline $\mathrm{pH}$; our simulation predicts that the dominant compound is $\left\{\mathrm{Ta}_{10}\right\}$. Although there is no experimental evidence of the formation of this compound, we justify our results based on Hatchett's assumption. Therefore, our program provides for the first time the formation constant $(\operatorname{logKf}=70.09)$ of the decatantalate. Notice that Figure 3 not only supplies information of the compounds that do appear, but also of the oxo-clusters that are not present. The values collected in Table 1 were used for calculating the phase diagrams depicted in Figure $3 \mathrm{~B}$ and $3 \mathrm{C}$. For example, Figure $3 \mathrm{C}$ top does not show the formation of $\left\{\mathrm{Ta}_{24}\right\}$, even though it was included in the simulation. Table 1 reveals that the formation constant of $\left\{\mathrm{Nb}_{24}\right\}$ is greater than the one for $\left\{\mathrm{Ta}_{24}\right\}$. Thus, the nucleation of the latter is less favored, which is consistent with the results depicted in Figure 3B and Figure 3C. A similar phenomenon occurs for the heptatantalate, $\left\{\mathrm{Ta}_{7}\right\}$, which does not appear either in the phase nor in the speciation diagrams. Again, if we compare the formation constants of the niobium and tantalum heptametalates (Table 1), we see that the former is greater than the latter. Consequently, and according to our predictions, none of these compounds will be formed. Next, the phase diagram at $\mathrm{pH}$ values greater than 9 included the tantalate Lindqvist's. In an analogous manner to niobates, Figure $3 \mathrm{C}$ top shows the presence of $\left\{\mathrm{H}_{2} \mathrm{Ta}_{6}\right\},\left\{\mathrm{HTa}_{6}\right\}$, and $\left\{\mathrm{Ta}_{6}\right\}$. However, $\left\{\mathrm{H}_{3} \mathrm{Ta}_{6}\right\}$ is also a minor species, and so, it only appears in the speciation diagram (Figure $3 \mathrm{C}$ bottom).

\section{Mechanistic Insights}


The self-assembly mechanisms to form large polyoxovanadates, -niobates, and -tantalates is far from obvious. Although their aqueous speciation is well-known (to a lesser extent for niobium and tantalum), their formation mechanisms are still unclear. Elucidating the nucleation pathways of polyoxometalates is paramount because it would improve the selectivity yields of their synthesis. However, a purely energy-based evaluation of the self-assembly mechanism can be misleading. In fact, reaction free energies do not account for the effect of the ionic force, $\mathrm{pH}$, and concentration. Nonetheless, our simulator offers the remarkable possibility to consider the latter variables in the mechanistic study because each speciation model must be solved at a fixed value of $\mathrm{pH}$, ionic force, and concentration. Additionally, each speciation model is defined by a unique set of chemical reactions. In this study, we are considering the following reaction types: protonation (acid/base), addition, condensation, hydrolysis and dimerization reactions. Then, if a successful speciation model is found, we automatically infer the nucleation mechanism. In the previous section we determined the speciation models that provided the best agreement with the experimental data. Figure 3 showed that polyoxovanadates had a different aqueous behavior compared to -niobates and -tantalates. Thus, the corresponding nucleation pathways will be distinct as well. Figure 4 depicts a schematic reaction map of the aggregation mechanisms for these three systems. Notice that the three families of POMs share multiple structures, the decametalate being the most iconic. Despite that, the nucleation mechanisms leading to the formation of $\left\{\mathrm{M}_{10}\right\}$ can be split into two classes: one class including the decavanadate, and a second class including the decaniobate and decatantalate.

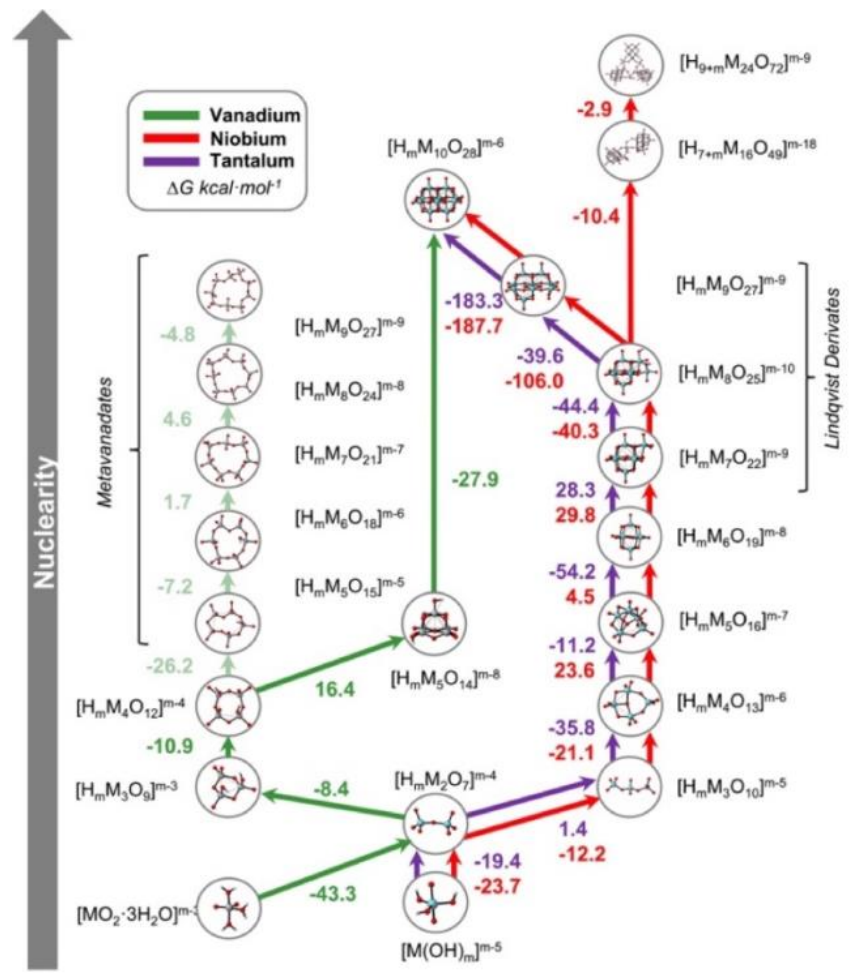

Figure 4. Nucleation mechanisms of polyoxovanadates (green), -niobates (red) and -tantalates (purple) according to the speciation models. Reaction free energies in $\mathrm{kcal} \cdot \mathrm{mol}^{-1}$. Tridimensional structures shown in circles.

On the left part of Figure 4, we see the nucleation pathway of polyoxovanadates. The polymerization starts with the smallest oxocluster in solution: vanadium monoxide. It can be found either in its tetrahedral form, $\left[\mathrm{H}_{\mathrm{x}} \mathrm{VO}_{4}\right]^{\mathrm{x}-3}$, or in its trigonal bipyramid form, $\left[\mathrm{VO}_{2} \cdot 3 \mathrm{H}_{2} \mathrm{O}\right]^{+}$. It is worth reminding that the process, even though exergonic, only happens at medium-high concentrations. Vanadium monoxide dimerizes spontaneously $\left(-43 \mathrm{kcal} \cdot \mathrm{mol}^{-1}\right)$ to form the dimeric specie $\left\{\mathrm{V}_{2}\right\}$. The nucleation proceeds in an exergonic manner up to the formation of the cyclic tetravanadate, $\left\{m-V_{4} O_{12}\right\}$. Actually, $\left\{m-V_{4} O_{12}\right\}$ is the first crossing point in the reaction map of vanadium since it can either undergo the formation of larger metavanadates (e.g. $\left\{m-V_{5} \mathrm{O}_{15}\right\},\left\{m-V_{6} \mathrm{O}_{16}\right\}$ ) or generate a newly proposed intermediate: $\left\{\mathrm{V}_{5}\right\}$. Both paths lead to the formation of stable clusters, but it is ultimately the $\mathrm{pH}$ and the total concentration that dictate the outcome. For example, at a pH between 6 and 8, the metavanadates are the most abundant species, while at a pH between 2 and 6 the decavanadate is the predominant compound. The formation of metavanadates is exergonic for the tetra- $\left(-10.9 \mathrm{kcal} \cdot \mathrm{mol}^{-1}\right)$, penta- $\left(-26.2 \mathrm{kcal} \cdot \mathrm{mol}^{-1}\right)$ and hexavanadate $\left(-7.2 \mathrm{kcal} \cdot \mathrm{mol}^{-1}\right)$. However, the nucleation of larger metavanadates is thermodynamically discouraged, in good agreement with the experimental data. ${ }^{20}$ Then, we proposed a reactive intermediate, $\left\{V_{5}\right\}$, as a transient species to form $\left\{V_{10}\right\}$. It is a very reactive cluster as its reaction free energy shows (+16.4 kcal.mol $\left.{ }^{1}\right)$. However, the dimerization reaction of $\left\{V_{5}\right\}$ leading to the decavanadate is strongly exergonic $\left(-27.9 \mathrm{kcal} \cdot \mathrm{mol}^{-1}\right)$. If we calculate the energy balance between both reactions, the outcome is negative $\left(-9.9 \mathrm{kcal} \cdot \mathrm{mol}^{-1}\right)$. Consequently, the overall formation of the decavanadate is spontaneous. Figure 3 can be also analyzed in combination with Figure 4 to further prove the existence of the $\left\{\mathrm{V}_{5}\right\}$. For example, Figure $3 \mathrm{~A}$ top shows that the regions including the decavanadates and the metavanadates are remarkably close. 
Therefore, it is reasonable to assume that there is a transient intermediate, such as $\left\{\mathrm{V}_{5}\right\}$, which connects both regions. The satisfactory results obtained in Figure 3 support our proposal about the role of $\left\{\mathrm{V}_{5}\right\}$ as a key intermediate for yielding the $\left\{\mathrm{V}_{10}\right\}$.

On the right part of Figure 4, we describe the nucleation pathway of polyoxoniobates and -tantalates. A first inspection of the reaction map suggests considerable differences between niobium and tantalum with respect to vanadium. For instance, POMSimulator predicts that the formation of the decametalate structure follows distinct paths depending on the metal center. From a chemical point of view, this is reasonable due to the divergence in $\mathrm{pH}$ behavior. Moreover, this evidence fully agrees with the experimental work published by Aureliano and coworkers. ${ }^{57}$ We will start first by describing the formation of the niobium oxoclusters. Figure 4 shows that the monomeric hydroxides are the smallest oxo-clusters in the niobium reaction network . These hydroxides display different geometries: trigonal pyramid $\left[\mathrm{Nb}(\mathrm{OH})_{3}\right]^{2+}$, tetrahedral $\left[\mathrm{Nb}(\mathrm{OH})_{4}\right]^{+}$, trigonal bipyramid $\mathrm{Nb}(\mathrm{OH})_{5}$, and octahedral $\left[\mathrm{Nb}(\mathrm{OH})_{6}\right]^{1-}$. The dominance of hydroxide-species is explained by the alkaline character of these polyoxometalates. High concentrations of hydroxide anions favor the likelihood of hydrolysis reactions. Although monomeric hydroxides do not appear as dominant species in Figure 3, this does not imply that they do not play a key role in the mechanism. In fact, they are actively involved in increasing the size of the oxo-clusters. Table $\mathrm{S} 2$ demonstrates that these small hydroxides appear in almost every condensation and addition reaction. The mechanism continues spontaneously with a first dimerization forming the $\left[\mathrm{Nb}_{2} \mathrm{O}_{7}\right]^{4-}\left(\left\{\mathrm{Nb}_{2}\right\}\right)$ dimer. Then a further condensation reaction takes place yielding the trimer $\left[\mathrm{Nb}_{3} \mathrm{O}_{10}\right]^{5-}\left(\left\{\mathrm{Nb}_{3}\right\}\right)$. From now on, the polymerization follows the socalled Lindqvist condensation pattern: $\left\{\mathrm{M}_{\mathrm{m}} \mathrm{O}_{3 \mathrm{~m}+1}\right\}$. Thus, $\left\{\mathrm{Nb}_{3}\right\}$ condensates spontaneously to $\left[\mathrm{Nb}_{4} \mathrm{O}_{13}\right]^{6-}\left(\left\{\mathrm{Nb}_{4}\right\}\right)$ with a reaction free energy of $-21.1 \mathrm{kcal} \cdot \mathrm{mol}^{-1}$. Next, the formation step for $\left[\mathrm{Nb}_{5} \mathrm{O}_{16}\right]^{6-}\left(\left\{\mathrm{Nb}_{5}\right\}\right)$ is slightly endergonic $\left(23.6 \mathrm{kcal} \cdot \mathrm{mol}^{-1}\right)$. Analogously, the generation of $\left\{\mathrm{Nb}_{6}\right\}$ is also endergonic, but the overall reaction energy is still exergonic. Therefore, the formation of $\left\{\mathrm{Nb}_{6}\right\}$ is thermodynamically favored. This evidence is directly seen in Figure 3B where the phase diagrams are dominated by the Lindqvist compounds, at different protonation rates. If we move beyond the Lindqvist structures, we find $\left\{\mathrm{Nb}_{10}\right\}$ and $\left\{\mathrm{Nb}_{24}\right\}$. Our research group performed a first study of the formation of not only the $\left\{\mathrm{Nb}_{10}\right\}$, but also of the $\left\{\mathrm{Nb}_{24}\right\}^{58}$ with the aim of honing these previous results by using our simulator. Thanks to having direct access to the speciation, we can also account for the effect of main variables such as: $\mathrm{pH}$, total concentration, and ionic force. In our previous work, we reported the decomposition mechanism of $\left\{\mathrm{Nb}_{10}\right\}$ to $\left\{\mathrm{Nb}_{7}\right\}$, promoted by $\mathrm{Cs}^{+}$and $\mathrm{Li}^{+}$cations. Additionally, we also highlighted that the cation had a non-innocent role in the reaction pathway. In the present study, we have employed $\mathrm{Na}^{+}$in our simulation since the ionic force was set to $0.1 \mathrm{M}$ of $\mathrm{NaCl}$. Therefore, we expect a similar, but not identical mechanism. Note that the effect of $\mathrm{Na}^{+}$is not considered in the DFT models but it is in the Davies equation. Figure 4 shows that the $\left\{\mathrm{Nb}_{10}\right\}$ and $\left\{\mathrm{Nb}_{7}\right\}$ are also related by condensation reactions, in agreement with our previous work. However, the $\mathrm{Cs}^{+}$mechanism involved an intramolecular reaction that yielded a cationic trimer, $\left.\left[\mathrm{Nb}_{3} \mathrm{O}_{6}(\mathrm{OH})_{3}\right)\right]^{2+}$, as a byproduct. Because the preference of this mechanism decays according to the alkali size $\left(\mathrm{Cs}^{+}>\mathrm{K}^{+}>\mathrm{Na}^{+}>\mathrm{Li}^{+}\right)$, we predict that the reaction will undergo a different path. In contrast to the formation of $\left\{\mathrm{V}_{10}\right\}$, POMSimulator does not predict as favorable the dimerization of $\left[\mathrm{Nb}_{5} \mathrm{O}_{14}\right]^{3-}\left(\left\{\mathrm{Nb}_{5}{ }^{*}\right\}\right)$ to form $\left\{\mathrm{Nb}_{10}\right\}$, thus confirming the experimental evidence that the $\left\{\mathrm{V}_{10}\right\}$ and $\left\{\mathrm{Nb}_{10}\right\}$ follow different nucleation mechanisms. ${ }^{57}$ In our previous work, we also reported a reaction equation for the formation of the $\left\{\mathrm{Nb}_{24}\right\}$. Three equivalents of $\left\{\mathrm{Nb}_{10}\right\}$ were needed to yield one equivalent of $\left\{\mathrm{Nb}_{24}\right\}$. However, two equivalents of a cationic niobate trimer, $\left.\left[\mathrm{Nb}_{3} \mathrm{O}_{6}(\mathrm{OH})_{3}\right)\right]^{2+}$, were also formed. In the present study we plan an improvement of our previous suggestion. Instead of three equivalents of $\left\{\mathrm{Nb}_{10}\right\}$, we propose three equivalents of $\left\{\mathrm{Nb}_{8}\right\}$, as depicted in Figure 4 . In this manner, we bypass the generation of unfavorable cationic niobates. The first equivalent would form the dimer $\left\{\mathrm{Nb}_{16}\right\}$, and the second one would yield $\left\{\mathrm{Nb}_{24}\right\}$. Both condensation reactions are spontaneous $\left(-10.4\right.$ and $\left.-2.9 \mathrm{kcal} \cdot \mathrm{mol}^{-1}\right)$ showing their thermochemical preference. Additionally, it is reasonable to proffer the existence of the $\left\{\mathrm{Nb}_{16}\right\}$ dimer following experimental precedents as the formation of the dimer $\left[\mathrm{Nb}_{14} \mathrm{O}_{40}\left(\mathrm{O}_{2}\right) \mathrm{H}_{3}\right]^{14-}$ reported by Nyman's group. ${ }^{26}$ Finally, this mechanism scheme would fit with the speciation results depicted in Figure 3. $\left\{\mathrm{Nb}_{10}\right\}$ is most stable oxo-cluster, in concordance with its large negative reaction free energy. If concentration effects are considered, the reaction can be shifted to the formation of $\left\{\mathrm{Nb}_{24}\right\}$ despite being less thermodynamically favored.

Figure 4 also summarizes the nucleation mechanism of polyoxotantalates. In this case, there is far less experimental data available. Notwithstanding, we suggest a formation pathway that leads to $\left\{\mathrm{Ta}_{6}\right\}$ and the unreported $\left\{\mathrm{Ta}_{10}\right\}$. Despite the fact that the latter cluster has not been detected in aqueous solution, we predict the mechanism in case the insolubility of $\left\{\mathrm{Ta}_{10}\right\}$ is ever overcome. Analogously to polyoxoniobates, the smallest tantalum oxo-clusters consist of monomeric hydroxides with the following geometries: trigonal pyramid $\left[\mathrm{Ta}(\mathrm{OH})_{3}\right]^{2+}$, tetrahedral $\left[\mathrm{Ta}(\mathrm{OH})_{4}\right]^{+}$, trigonal bipyramid $\mathrm{Ta}(\mathrm{OH})_{5}$, and octahedral $\left[\mathrm{Ta}(\mathrm{OH})_{6}\right]^{1-}$. The monomer dimerizes to yield $\left[\mathrm{Ta}_{2} \mathrm{O}_{7}\right]^{4-}\left(\left\{\mathrm{Ta}_{2}\right\}\right)$ spontaneously $\left(-19.4 \mathrm{kcal} \cdot \mathrm{mol}^{-1}\right)$. The formation of the trimer $\left[\mathrm{Ta}_{3} \mathrm{O}_{10}\right]^{5-}\left(\left\{\mathrm{Ta}_{3}\right\}\right)$ is less favored $\left(1.4 \mathrm{kcal} \cdot \mathrm{mol}^{-1}\right)$ but the next reactions are exergonic. For instance, the generation of the tetramer, $\left[\mathrm{Ta}_{4} \mathrm{O}_{13}\right]^{6-}\left(\left\{\mathrm{Ta}_{4}\right\}\right), \mathrm{and}$ pentamer, $\left[\mathrm{Ta}_{5} \mathrm{O}_{16}\right]^{7-}\left(\left\{\mathrm{Ta}_{5}\right\}\right)$ show large negative reaction free energies: -35.8 and $-11.2 \mathrm{kcal} \cdot \mathrm{mol}^{-1}$. Next, $\left\{\mathrm{Ta}_{5}\right\}$ condensates to form the main cluster in polyoxotantalates' chemistry: the Lindqvist $\left\{\mathrm{Ta}_{6}\right\}$. Figure 3 shows that $\left\{\mathrm{H}_{\mathrm{x}} \mathrm{Ta}_{6}\right\}$ dominates most of the phase diagram. If we acidify the media, $\left\{\mathrm{Ta}_{6}\right\}$ condensates to $\left\{\mathrm{Ta}_{7}\right\}$ even though it does not appear as the most abundant compound at any range of $\mathrm{pH}$. This reveals the important effect of the $\mathrm{pH}$ and concentration. Although the reaction free energy for $\left\{\mathrm{Ta}_{7}\right\}$ and $\left\{\mathrm{Nb}_{7}\right\}$ is remarkably similar, only the niobium analogue becomes abundant. That is why a strict energetic picture of the nucleation can lead to wrong conclusions. In contrast, equilibrium constants, such as the ones reported in Table 1, do capture other important variables such as ionic force and concentration effects. To generate the decatantalate, $\left\{\mathrm{Ta}_{7}\right\}$ undergoes three consecutive condensations: first to yield $\left\{\mathrm{Ta}_{8}\right\}\left(-44.4 \mathrm{kcal} \cdot \mathrm{mol}^{-1}\right)$, then $\left\{\mathrm{Ta}_{9}\right\}\left(-106.0 \mathrm{kcal} \cdot \mathrm{mol}^{-1}\right)$, and finally $\left\{\mathrm{Ta}_{10}\right\}\left(-187.7 \mathrm{kcal} \cdot \mathrm{mol}^{-1}\right)$. The full process is incredibly spontaneous, with a large negative reaction free energy. However, there are experimental studies that report the formation of $\left\{\mathrm{Ta}_{24}\right\}$, either in aqueous or non-aqueous media. This evidence is also in good agreement with the prediction of our simulator. 
Although tantalum and niobium share the same type of molecular set, our method automatically assesses that $\left\{\mathrm{Nb}_{24}\right\}$ is more stable than $\left\{\mathrm{Ta}_{24}\right\}$.

\section{CONCLUSIONS}

In this work we have not only reproduced, but also predicted the $\mathrm{pH}$-dependent and concentration- dependent speciation, and proposed nucleation mechanisms of polyoxovanadates, -niobates, and -tantalates. First, we propose an unprecedent oxo-cluster $\left\{\mathrm{V}_{5}\right\}$ that acts as a transient intermediate in the formation of $\left\{\mathrm{V}_{10}\right\}$. We argue that $\left\{\mathrm{V}_{5}\right\}$ connects the two main speciation $\mathrm{pH}$ regions (decavanadates and metavanadates) of vanadium oxo-clusters. Overall, the condensation reaction of $\left\{\mathrm{m}-\mathrm{V}_{4}\right\}$ to form $\left\{\mathrm{V}_{5}\right\}$ and the dimerization of $\left\{\mathrm{V}_{5}\right\}$ to yield $\left\{\mathrm{V}_{10}\right\}$ happen in an exergonic manner. Indeed, the phase and speciation diagrams in Figure $3 \mathrm{~A}$ are in particularly good agreement with the experimental data. Furthermore, we report for the first time the formation constants of $\left\{\mathrm{Nb}_{10}\right\},\left\{\mathrm{Nb}_{24}\right\}$ and $\left\{\mathrm{Nb}_{7}\right\}$. Consequently, we can predict the phase diagram, which so far had been restricted to $\left\{\mathrm{H}_{x} \mathrm{Nb}_{6}\right\}-\mathrm{derivatives}$. Furthermore, we have employed our new-developed method to make slight improvements to our previous mechanism concerning the formation of $\left\{\mathrm{Nb}_{10}\right\}$ and $\left\{\mathrm{Nb}_{24}\right\}$. Finally, we have predicted the formation of polyoxotantalates' speciation. We have found $\left\{\mathrm{Ta}_{6}\right\}$ as the most abundant compound, but we have also reported the hypothetical formation constant of $\left\{\mathrm{Ta}_{10}\right\}$ in solution. We suggest that the nucleation process to yield $\left\{\mathrm{Ta}_{10}\right\}$ would happen in similar fashion to $\left\{\mathrm{Nb}_{10}\right\}$. Additionally, we have not found any evidence of the formation of $\left\{\mathrm{Ta}_{24}\right\}$ in our simulation, in good agreement with the experiments.

In earlier works, we showed that POMSimulator supplied excellent results for polyoxomolybdates and -tungstanates. With the results presented above in hand, we have proved that our method can be successfully applied to three different families of polyoxometalates. Not only to polyoxovanadates (which are rather like molybdenum and tungsten), but also to -niobates and tantalates. The results achieved for niobium and tantalum oxo-clusters are especially helpful since experiments must deal with insolubility problems. Thanks to the in-silico approach of our method, we can bypass the solubility issue and gain insight into the chemical stability and abundance of new molecular metal oxides.

\section{ASSOCIATED CONTENT}

The Supporting Information is available free of charge at $X$

Molecular sets, computational details, overview of the Python code developed, full list of chemical reactions, and speciation models and formation constants plus additional data.

\section{Corresponding Author}

* cbo@iciq.cat

\section{Present Addresses}

tIf an author's address is different than the one given in the affiliation line, this information may be included here.

\section{Author Contributions}

The manuscript was written through contributions of all authors.

\section{ACKNOWLEDGMENTS}

This work was supported by the Spanish Ministerio de Ciencia e Innovación through project PID2020-112806RB-I00 and through the Severo Ochoa Excellence Accreditation 2020-2023 (CEX2019-000925-S, MCI/AEI), the ICIQ Foundation and the CERCA Program of the Generalitat de Catalunya.

\section{REFERENCES}

(1) Vilà-Nadal, L.; Cronin, L. Design and Synthesis of Polyoxometalate-Framework Materials from Cluster Precursors. Nature Reviews Materials 2017, 2 (10), 17054.

(2) Gumerova, N. I.; Rompel, A. Synthesis, Structures and Applications of Electron-Rich Polyoxometalates. Nature Reviews Chemistry 2018, 2 (2), 0112.

(3) Anjass, M.; Lowe, G. A.; Streb, C. Molecular Vanadium Oxides for Energy Conversion and Energy Storage: Current Trends and Emerging Opportunities. Angewandte Chemie - International Edition 2021, 60 (14), 7522-7532. 
(4) Zhong, J.; Pérez-Ramírez, J.; Yan, N. Biomass Valorisation over Polyoxometalate-Based Catalysts. Green Chemistry 2021, 23 (1), 1836.

(5) Rahman, T.; Martin, N. P.; Jenkins, J. K.; Elzein, R.; Fast, D. B.; Addou, R.; Herman, G. S.; Nyman, M. Nb2O5 , LiNbO3 , and (Na, K)NbO3 Thin Films from High-Concentration Aqueous Nb-Polyoxometalates. Inorganic Chemistry 2022, acs.inorgchem.1c03638.

(6) Gumerova, N. I.; Rompel, A. Polyoxometalates in Solution: Speciation under Spotlight. Chemical Society Reviews 2020, 49 (21), 75687601.

(7) Misra, A.; Kozma, K.; Streb, C.; Nyman, M. Beyond Charge Balance: Counter-Cations in Polyoxometalate Chemistry. Angewandte Chemie - International Edition 2020, 59 (2), 596-612.

(8) Müller, A.; Beckmann, E.; Bögge, H.; Schmidtmann, M.; Dress, A. Inorganic Chemistry Goes Protein Size: A Mo 368 Nano-Hedgehog Initiating Nanochemistry by Symmetry Breaking. Angewandte Chemie - International Edition 2002, 41 (7), 1162-1167.

(9) Zhan, C. H.; Winter, R. S.; Zheng, Q.; Yan, J.; Cameron, J. M.; Long, D. L.; Cronin, L. Assembly of Tungsten-Oxide-Based Pentagonal Motifs in Solution Leads to Nanoscale $\{\mathrm{W} 48\},\{\mathrm{W} 56\}$, and $\{\mathrm{W} 92\}$ Polyoxometalate Clusters. Angewandte Chemie - International Edition 2015, 54 (48), 14308-14312.

(10) Nyman, M. Polyoxoniobate Chemistry in the 21st Century. Dalton Transactions 2011, 40 (32), 8049.

(11) Deblonde, G. J. P.; Moncomble, A.; Cote, G.; Bélair, S.; Chagnes, A. Experimental and Computational Exploration of the UV-Visible Properties of Hexaniobate and Hexatantalate Ions. RSC Advances 2015, 5 (10), 7619-7627.

(12) Pettersson, L. Equilibria of Polyoxometalates in Aqueous Solution. Molecular Engineering 1993, 3 (1), $29-42$.

(13) Walanda, D. K.; Burns, R. C.; Lawrance, G. A.; von Nagy-Felsobuki, E. I. New Isopolyoxovanadate lons Identified by Electrospray Mass Spectrometry. Inorganic Chemistry Communications 1999, 2 (10), 487-489.

(14) J.-M. Tarascon, M. Armand, Nature 2001, 414, 359-367.

(15) Li, F.; Carpenter, S. H.; Higgins, R. F.; Hitt, M. G.; Brennessel, W. W.; Ferrier, M. G.; Cary, S. K.; Lezama-Pacheco, J. S.; Wright, J. T.; Stein, B. W.; et al. Polyoxovanadate-Alkoxide Clusters as a Redox Reservoir for Iron. Inorganic Chemistry 2017, 56 (12), 7065-7080.

(16) Murugesan, V.; Nie, Z.; Zhang, X.; Gao, P.; Zhu, Z.; Huang, Q.; Yan, L.; Reed, D.; Wang, W. Accelerated Design of Vanadium Redox Flow Battery Electrolytes through Tunable Solvation Chemistry. Cell Reports Physical Science 2021, 2 (2), 100323.

(17) Greiner, S.; Anjass, M. H.; Fichtner, M.; Streb, C. Solid-State-Stabilization of Molecular Vanadium Oxides for Reversible Electrochemical Charge Storage. Inorganic Chemistry Frontiers 2020, 7 (1), 134-139.

(18) Streb, C. New Trends in Polyoxometalate Photoredox Chemistry: From Photosensitisation to Water Oxidation Catalysis. Dalton Transactions 2012, 41 (6), 1651-1659.

(19) Schwarz, B.; Forster, J.; Goetz, M. K.; Yücel, D.; Berger, C.; Jacob, T.; Streb, C. Visible-Light-Driven Water Oxidation by a Molecular Manganese Vanadium Oxide Cluster. Angewandte Chemie - International Edition 2016, 55 (21), 6329-6333.

(20) Aureliano, M.; Crans, D. C. Decavanadate (V10O286-) and Oxovanadates: Oxometalates with Many Biological Activities. Journal of Inorganic Biochemistry 2009, 103 (4), 536-546.

(21) Samart, N.; Arhouma, Z.; Kumar, S.; Murakami, H. A.; Crick, D. C.; Crans, D. C. Decavanadate Inhibits Mycobacterial Growth More Potently Than Other Oxovanadates. Frontiers in Chemistry 2018, 6, 1-16.

(22) Fukuda, N.; Yamase, T. In Vitro Antibacterial Activity of Vanadate and Vanadyl Compounds against Streptococcus Pneumoniae. Biological and Pharmaceutical Bulletin 1997, 20 (8), 927-930.

(23) Shah, H. S.; Al-Oweini, R.; Haider, A.; Kortz, U.; Iqbal, J. Cytotoxicity and Enzyme Inhibition Studies of Polyoxometalates and Their Chitosan Nanoassemblies. Toxicology Reports 2014, 1, 341-352.

(24) Aureliano, M.; Ohlin, C. A. Decavanadate in Vitro and in Vivo Effects: Facts and Opinions. Journal of Inorganic Biochemistry 2014, $137,123-130$.

(25) Zhao, H. Y.; Li, Y. Z.; Zhao, J. W.; Wang, L.; Yang, G. Y. State-of-the-Art Advances in the Structural Diversities and Catalytic Applications of Polyoxoniobate-Based Materials. Coordination Chemistry Reviews 2021, 443, 213966. 
(26) Martin, N. P.; Petrus, E.; Segado, M.; Arteaga, A.; Zakharov, L. N.; Bo, C.; Nyman, M. Strategic Capture of the \{Nb7\} Polyoxometalate. Chemistry - A European Journal 2019, 10580-10584.

(27) Bontchev, R. P.; Nyman, M. Evolution of Polyoxoniobate Cluster Anions. Angewandte Chemie - International Edition 2006, 45 (40), 6670-6672.

(28) Tsunashima, R.; Long, D. L.; Miras, H. N.; Gabb, D.; Pradeep, C. P.; Cronin, L. The Construction of High-Nuclearity Isopolyoxoniobates with Pentagonal Building Blocks: [HNb27O76]16- and [H 10Nb31093(CO3)]23-. Angewandte Chemie - International Edition 2010, 49 (1), 113-116.

(29) Huang, P.; Qin, C.; Su, Z.; Xing, Y.; Wang, X.-L.; Shao, K.; Lan, Y.; Wang, E. Self-Assembly and Photocatalytic Properties of Polyoxoniobates: \{Nb 24072$\},\{\mathrm{Nb} 32096\}$, and \{K 12 Nb 960288$\}$ Clusters. Journal of the American Chemical Society 2012, 134 (34), 14004-14010.

(30) Jin, L.; Zhu, Z. K.; Wu, Y. L.; Qi, Y. J.; Li, X. X.; Zheng, S. T. Record High-Nuclearity Polyoxoniobates: Discrete Nanoclusters \{Nb114\}, $\{\mathrm{Nb81}\}$, and $\{\mathrm{Nb52}\}$, and Extended Frameworks Based on $\{\mathrm{Cu} 3 \mathrm{Nb} 78\}$ and $\{\mathrm{Cu} 4 \mathrm{Nb} 78\}$. Angewandte Chemie - International Edition 2017, 56 (51), 16288-16292.

(31) Wu, Y.-L.; Wang, Y.-J.; Sun, Y.-Q.; Li, X.-X.; Zheng, S.-T. Two High-Nuclearity Isopolyoxoniobates Containing \{Nb 54 O 151 \}-Based Helical Nanotubes for the Decomposition of Chemical Warfare Agent Simulants. Chemical Communications 2022, $29,4-7$.

(32) Chabauty, A. L.; Campayo, L.; Méar, F. O.; Montagne, L. Niobium- and Bismuth-Silver Phosphate Glasses for the Conditioning of Radioactive lodine. Journal of Non-Crystalline Solids 2019, 510 (December 2018), 51-61.

(33) Maksimchuk, N. v.; Ivanchikova, I. D.; Maksimov, G. M.; Eltsov, I. v.; Evtushok, V. Yu.; Kholdeeva, O. A.; Lebbie, D.; Errington, R. J.; Solé-Daura, A.; Poblet, J. M.; et al. Why Does Nb(V) Show Higher Heterolytic Pathway Selectivity Than Ti(IV) in Epoxidation with $\mathrm{H} 2$ O 2 ? Answers from Model Studies on Nb- and Ti-Substituted Lindqvist Tungstates. ACS Catalysis 2019, 9 (7), $6262-6275$.

(34) Evtushok, V. Y.; Ivanchikova, I. D.; Lopatkin, V. A.; Maksimchuk, N. v.; Podyacheva, O. Y.; Suboch, A. N.; Stonkus, O. A.; Kholdeeva, $\mathrm{O}$. A. Heterolytic Alkene Oxidation with $\mathrm{H} 2 \mathrm{O} 2$ catalyzed by Nb-Substituted Lindqvist Tungstates Immobilized on Carbon Nanotubes. Catalysis Science and Technology 2021, 11 (9), 3198-3207.

(35) Anderson, T. M.; Rodriguez, M. A.; Bonhomme, F.; Bixler, J. N.; Alam, T. M.; Nyman, M. An Aqueous Route to [Ta6019]8- and SolidState Studies of Isostructural Niobium and Tantalum Oxide Complexes. Journal of the Chemical Society. Dalton Transactions 2007, 9226 (40), 4517-4522.

(36) Filella, M.; May, P. M. The Aqueous Solution Thermodynamics of Tantalum under Conditions of Environmental and Biological Interest. Applied Geochemistry 2019, 109 (April), 104402

(37) Fullmer, L. B.; Molina, P. I.; Antonio, M. R.; Nyman, M. Contrasting Ion-Association Behaviour of Ta and Nb Polyoxometalates. Dalton Transactions 2014, 43 (41), 15295-15299.

(38) Son, J. H.; Casey, W. H. Titanium-Substituted Polyoxotantalate Clusters Exhibiting Wide PH Stabilities: [Ti2Ta8O28]8-and [Ti12Ta6044]10-. Chemistry - A European Journal 2016, 22 (40), 14155-14157.

(39) Matsumoto, M.; Ozawa, Y.; Yagasaki, A.; Zhe, Y. Decatantalate - The Last Member of the Group 5 Decametalate Family. Inorganic Chemistry 2013, 52 (14), 7825-7827.

(40) Sudrajat, H.; Kitta, M.; Ito, R.; Nagai, S.; Yoshida, T.; Katoh, R.; Ohtani, B.; Ichikuni, N.; Onishi, H. Water-Splitting Activity of La-Doped NaTaO3Photocatalysts Sensitive to Spatial Distribution of Dopants. Journal of Physical Chemistry C 2020, 124 (28), 15285-15294.

(41) Kumar, S.; Kumar, H.; Vura, S.; Pratiyush, A. S.; Charan, V. S.; Dolmanan, S. B.; Tripathy, S.; Muralidharan, R.; Nath, D. N. Investigation of Ta 2 O 5 as an Alternative High-k Dielectric for InAIN/GaN MOS-HEMT on Si. IEEE Transactions on Electron Devices 2019, 66 (3), 1230-1235.

(42) López, X.; Carbó, J. J.; Bo, C.; Poblet, J. M. Structure, Properties and Reactivity of Polyoxometalates: A Theoretical Perspective. Chemical Society Reviews 2012, 41 (22), 7537-7571.

(43) Unsleber, J. P.; Reiher, M. The Exploration of Chemical Reaction Networks. Annual Review of Physical Chemistry 2020, 71 (1), $121-$ 142.

(44) Wolos, A.; Roszak, R.; Zadlo-Dobrowolska, A.; Beker, W.; Mikulak-Klucznik, B.; Spólnik, G.; Dygas, M.; Szymkuc, S.; Grzybowski, B. A. Synthetic Connectivity, Emergence, and Self-Regeneration in the Network of Prebiotic Chemistry. Science 2020, 369 (6511). 
(45) Jinich, A.; Sanchez-Lengeling, B.; Ren, H.; Goldford, J. E.; Noor, E.; Sanders, J. N.; Segrè, D.; Aspuru-Guzik, A. A Thermodynamic Atlas of Carbon Redox Chemical Space. Proceedings of the National Academy of Sciences of the United States of America 2021, $117(52)$, 32910-32918.

(46) McDermott, M. J.; Dwaraknath, S. S.; Persson, K. A. A Graph-Based Network for Predicting Chemical Reaction Pathways in SolidState Materials Synthesis. Nature Communications 2021, 12 (1), 3097.

(47) Garay-Ruiz, D.; Álvarez-Moreno, M.; Bo, C.; Martínez-Núñez, E. New Tools for Taming Complex Reaction Networks: The Unimolecular Decomposition of Indole Revisited. ACS Physical Chemistry Au 2022, acsphyschemau.1c00051.

(48) Petrus, E.; Segado, M.; Bo, C. Nucleation Mechanisms and Speciation of Metal Oxide Clusters. Chemical Science 2020, 11 (32), 84488456.

(49) Petrus, E.; Bo, C. Unlocking Phase Diagrams for Molybdenum and Tungsten Nanoclusters and Prediction of Their Formation Constants. The Journal of Physical Chemistry A 2021, 125 (23), 5212-5219.

(50) Petrus, E.; Segado, M.; Bo, C. ioChem Data Collection https://iochem-bd.iciq.es/browse/reviewcollection/100/30179/98e0d4f07609eeb237a481e1.

(51) Àlvarez, M.; M.; Graaf, C.; López, N.; Maseras, F.; Poblet, M, J.; Bo, C. ; Managing the Computational Chemistry Big Data Problem: The loChem-BD Platform. J. Chem. Inf. Model. 2015, 55, 95-103.

(52) Sures, D. J.; Nagabhushana, G. P.; Navrotsky, A.; Nyman, M. Thermochemical Measurements of Alkali Cation Association to Hexatantalate. Molecules 2018, 23 (10), 1-9.

(53) Petrus, E.; Segado, M.; Bo, C. Nucleation Mechanisms and Speciation of Metal Oxide Clusters. Chemical Science 2020, 11 (32), 84488456.

(54) Petrus, E.; Bo, C. Unlocking Phase Diagrams for Molybdenum and Tungsten Nanoclusters and Prediction of Their Formation Constants. The Journal of Physical Chemistry A 2021, 125 (23), 5212-5219.

(55) Elvingson, K.; González Baró, A.; Pettersson, L. Speciation in Vanadium Bioinorganic Systems. 2. An NMR, ESR, and Potentiometric Study of the Aqueous H+-Vanadate-Maltol System. Inorganic Chemistry 1996, 35 (11), 3388-3393.

(56) Etxebarria, N.; Fernández, L. A.; Madariaga, J. M. On the Hydrolysis of Niobium(V) and Tantalum(V) in $3 \mathrm{Mol} \mathrm{Dm}-3 \mathrm{KCl}$ at $25^{\circ} \mathrm{C}$. Part 1. Construction of a Thermodynamic Model for NbV. Journal of the Chemical Society, Dalton Transactions 1994, No. 20, 3055-3059.

(57) Aureliano, M.; Ohlin, C. A.; Vieira, M. O.; Marques, M. P. M.; Casey, W. H.; Batista De Carvalho, L. A. E. Characterization of Decavanadate and Decaniobate Solutions by Raman Spectroscopy. Dalton Transactions 2016, 45 (17), 7391-7399.

(58) Sures, D.; Segado, M.; Bo, C.; Nyman, M. Alkali-Driven Disassembly and Reassembly of Molecular Niobium Oxide in Water. Journal of the American Chemical Society 2018, 140 (34), 10803-10813.

(59) Villa, E. M.; Ohlin, C. A.; Balogh, E.; Anderson, T. M.; Nyman, M. D.; Casey, W. H. Reaction Dynamics of the Decaniobate lon [HxNb 10028](6-x)- in Water. Angewandte Chemie - International Edition 2008, 47 (26), 4844-4846.

(60) Klemperer, W. G.; Marek, K. A. An 170 NMR Study of Hydrolyzed NbV in Weakly Acidic and Basic Aqueous Solutions. European Journal of Inorganic Chemistry 2013, 28 (10-11), 1762-1771. 
Insert Table of Contents artwork here

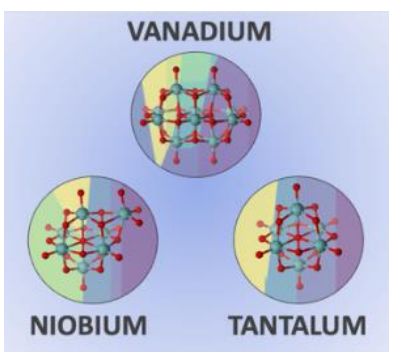

